OPEN ACCESS

Edited by:

Marian Brestic,

Slovak University of Agriculture,

Slovakia

Reviewed by:

Magda Pál,

Hungarian Academy of Sciences,

Hungary

Zhenjiang Zhou,

Swedish University of Agricultural

Sciences, Sweden

Jie Kuai,

Huazhong Agricultural University,

China

*Correspondence:

Xiangnan $\mathrm{Li}$

lixiangnan@iga.ac.cn

Specialty section:

This article was submitted to

Plant Abiotic Stress,

a section of the journal

Frontiers in Plant Science

Received: 03 May 2018

Accepted: 11 June 2018

Published: 04 July 2018

Citation:

Zhu X, Liu S, Sun L, Song F, Liu F and

LiX (2018) Cold Tolerance

of Photosynthetic Electron Transport System Is Enhanced in Wheat Plants

Grown Under Elevated $\mathrm{CO}_{2}$.

Front. Plant Sci. 9:933.

doi: 10.3389/fpls.2018.00933

\section{Cold Tolerance of Photosynthetic Electron Transport System Is Enhanced in Wheat Plants Grown Under Elevated $\mathrm{CO}_{2}$}

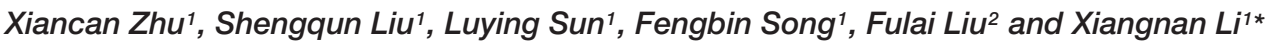 \\ ${ }^{1}$ Northeast Institute of Geography and Agroecology, Chinese Academy of Sciences, Changchun, China, ${ }^{2}$ Department of \\ Plant and Environmental Sciences, Faculty of Science, University of Copenhagen, Copenhagen, Denmark
}

The effects of $\mathrm{CO}_{2}$ elevation on sensitivity of photosynthetic electron transport system of wheat in relation to low temperature stress are unclear. The performance of photosynthetic electron transport system and antioxidant system in chloroplasts was investigated in a temperature sensitive wheat cultivar Lianmai6 grown under the combination of low temperature (2 days at $2 /-1^{\circ} \mathrm{C}$ in the day/night) and $\mathrm{CO}_{2}$ elevation $\left(800 \mu \mathrm{mol} \mathrm{I}{ }^{-1}\right)$. It was found that $\mathrm{CO}_{2}$ elevation increased the efficiency of photosynthetic electron transport in wheat exposed to low temperature stress, which was related to the enhanced maximum quantum yield for electron transport beyond $Q_{A}$ and the increased quantum yield for reduction of end electron acceptors at the PSI acceptor side in plants under elevated $\mathrm{CO}_{2}$. Also, under low temperature, the activities of ATPases, ascorbate peroxidase, and catalase in chloroplasts were enhanced in wheat under elevated $\mathrm{CO}_{2}$. It suggested that the cold tolerance of photosynthetic electron transport system is enhanced by $\mathrm{CO}_{2}$ elevation.

Keywords: cold tolerance, Triticum aestivum, photosynthesis, chlorophyll a fluorescence, $\mathrm{CO}_{2}$ elevation

\section{INTRODUCTION}

Low temperature stress is one of the most critical environmental stimuli affecting crop plant growth and grain yield. As a temperate plant, wheat is tolerant to some lower temperatures during the vegetative stage, but it is very sensitive to low temperature stress during the reproductive stage (Whaley et al., 2004). In North Europe, spring wheat is frequently suffering from frost damage in late May and early June when the plants commence reproductive stage. Studies have shown that the low temperature during vegetative stage could cause yield loss up to $10 \%$ (Frederiks et al., 2012). The cold-induced damage to photosynthetic apparatus is the key limitation in energy supply to plant growth. Photosynthesis converts light energy into ATP and redox equivalents (NADPH), which is the primary metabolic sink for plant growth (Ruelland et al., 2009). Low temperature stress rapidly affects the photosynthesis by direct and indirect effects (Thakur and Nayyar, 2013). For instance, low temperature stress increases membrane viscosity and restricts the diffusion of plastoquinone, to inhibit the thylakoid electron transport (Thakur and Nayyar, 2013). Light energy trapping by the antenna of PSI and PSII and its contribution to drive charge-separation in the reaction centers (RCs) is easily disturbed by low temperature, due to the chlorophyll antenna complexes trap more energy than that can be processed biochemically (Ensminger et al., 2006). 
Under such circumstances, thylakoid membranes become overenergized. One of the consequences of this over-energized state is photodamage, primarily caused by the overproduction of reactive oxygen species (ROS) (Ashraf and Harris, 2013). Low temperature stress often associates with ROS accumulation. It has been well documented that the activities of the scavenging enzymes are lowered by low temperature stress (Li et al., 2013); hence, the scavenging systems cannot counterbalance the ROS formation that is always associated with chloroplastic electron transfer reactions (Li et al., 2014).

It has been well documented that the increasing atmospheric $\mathrm{CO}_{2}$ concentration (hereafter abbreviated to $\left[\mathrm{CO}_{2}\right]$ ) has both direct and indirect effects on plant growth and stress responses in wheat (Li et al., 2001; Pinter et al., 2001; Medina et al., 2016; Varga et al., 2017). For instance, elevated $\left[\mathrm{CO}_{2}\right]$ has a direct and positive effect on the photosynthesis of wheat plants and thus stimulates plant growth along with impacts on other physiological processes including nitrogen metabolism (Stitt and Krapp, 1999; Wang et al., 2013). Almost all studies showed the mitigation effects of elevated $\left[\mathrm{CO}_{2}\right]$ on abiotic stress in wheat (Shanmugam et al., 2013; Medina et al., 2016; Li et al., 2017).

The heat stress is considered to occur always along with $\left[\mathrm{CO}_{2}\right]$ elevation in future climate, and many researches has focused on the combined effects of heat stress and $\left[\mathrm{CO}_{2}\right]$ elevation on wheat (Sanchez de la Puente et al., 2000; Dias de Oliveira et al., 2013; Benlloch-Gonzalez et al., 2014; Vicente et al., 2015). The increased climatic variability also leads greater risk of the crop being exposure to the extreme low temperature stress (Mäkinen et al., 2017). However, less attention has been paid to the interaction of $\left[\mathrm{CO}_{2}\right]$ elevation and low temperatures. In this study, the performance of the photosynthetic electron transport system in wheat plants under the combination of low temperature and $\left[\mathrm{CO}_{2}\right]$ elevation was analyzed. It was hypothesized that the response of photosynthetic electron transport system to cold stress in wheat is affected by $\left[\mathrm{CO}_{2}\right]$ elevation.

\section{MATERIALS AND METHODS}

\section{Experimental Design and Materials}

A cold sensitive wheat cultivar Lianmai6 was used in a pot experiment at ambient $\left(400 \mu \mathrm{mol} \mathrm{l} \mathrm{l}^{-1}\right.$, for ambient $\left[\mathrm{CO}_{2}\right]$ treatment) and elevated $\left[\mathrm{CO}_{2}\right]\left(800 \mu \mathrm{mol} \mathrm{l}^{-1}\right.$, for elevated $\left[\mathrm{CO}_{2}\right]$ treatment), respectively, from September 15 to February 15 in 2015. Four seeds of wheat cv. Lianmai6 were sown in each pot, filled with $4.8 \mathrm{~kg}$ of sandy loam. Before filling the pots, the soil was pre-mixed with $2 \mathrm{~g} \mathrm{~N}, 1 \mathrm{~g} \mathrm{P}_{2} \mathrm{O}$, and $1.4 \mathrm{~g} \mathrm{~K}_{2} \mathrm{O}$ per pot, and no additional fertilization was applied in later stages.

\section{Treatments}

From sowing, half of the plants were grown in the greenhouse cell with ambient $\left[\mathrm{CO}_{2}\right]$ (400 ppm, a $\left[\mathrm{CO}_{2}\right]$ ), and another half were grown in the cell with elevated $\left[\mathrm{CO}_{2}\right](800 \mathrm{ppm}$, $\left.\mathrm{e}\left[\mathrm{CO}_{2}\right]\right)$. The elevated $\left[\mathrm{CO}_{2}\right]$ treatment was applied by emission of pure $\mathrm{CO}_{2}$ from a bottle tank, released in one point and distributed in the phytotrons through internal ventilation (Yan et al., 2017). The $\left[\mathrm{CO}_{2}\right]$ in the greenhouse was monitored every six seconds by $\mathrm{CO}_{2}$ Transmitter Series GMT220 (Vaisala, Helsinki, Finland) during the whole growing season. At the head emerging stage (Zadoks 50), half of wheat plants in each cell were transferred into low temperature phytotrons for a 2-day low temperature stress treatment $\left(2 /-1^{\circ} \mathrm{C}\right.$ in the day/night). The rest of wheat plants were grown under the normal temperature $\left(26 / 16^{\circ} \mathrm{C}\right.$ in the day/night). The other environmental condition in low temperature phytotrons was set as the same as that in normal temperature phytotrons. Therefore, four treatments were included: $\mathrm{EN}$, elevated $\left[\mathrm{CO}_{2}\right]+$ normal temperature; $\mathrm{AN}$, ambient $\left[\mathrm{CO}_{2}\right]+$ normal temperature; $\mathrm{EL}$, elevated $\left[\mathrm{CO}_{2}\right]$ + low temperature stress; and $\mathrm{AL}$, ambient $\left[\mathrm{CO}_{2}\right]+$ low temperature stress. The experiment was a randomized block design. Each treatment had four replicates, and each replicate consisted of 5 pots. The flag leaves in each replicate were collected for chloroplast isolation and measurements of ATPase and antioxidant enzyme activity, just after the chlorophyll $a$ fluorescence measurement.

\section{Chlorophyll a Fluorescence}

The fast chlorophyll a fluorescence induction curve was measured on the flag leaf just after low temperature treatment using a Plant Efficiency Analyzer (Pocket-PEA; Hansatech, Norfolk, United Kingdom). Before measuring, plants were dark adapted for $0.5 \mathrm{~h}$. The collected data were processed by the program PEA Plus 1.04, and Biolyzer 3.0 software $^{1}$ (Bioenergetics Laboratory, Geneva, Switzerland) was used to calculate the fast chlorophyll $a$ fluorescence induction (OJIP) test parameters.

\section{Chloroplasts Isolation and ATPase Activity}

Leaf samples $(6 \mathrm{~g})$ were ground in $30 \mathrm{~mL}$ of extraction buffer [0.45 M sucrose, $15 \mathrm{mM}$ 3-(N-morpholino) propanesulfonic acid (MOPS), $1.5 \mathrm{mM}$ ethylene glycol tetra acetic acid (EGTA), $0.6 \%$ polyvinylpyrro-lidone (PVP), $0.2 \%$ bovine serum albumine (BSA), $0.2 \mathrm{mM}$ phenylmethylsulphonyl fluoride (PMSF), and $10 \mathrm{mM}$ dithiothreitol (DTT)]. Homogenate was filtered through gauze (8 layers), and the filtrate was centrifuged at $2000 \times g$ for $5 \mathrm{~min}$. The sedimentation was resuspended with sorbitol resuspension medium [SRM, 0.33 $\mathrm{M}$ sorbitol in $50 \mathrm{mM} 4-(2-$ hydroxyethyl)-1-piperazineethanesulfonic acid] and layered on the top of a layered system $(7 \mathrm{~mL}, 35 \%, 80 \%$ Percoll $)$ for the step gradients. The chloroplasts were collected and washed with $2 \mathrm{~mL}$ SRM followed by centrifugation at $1100 \times g$ for $10 \mathrm{~min}$. The activities of $\mathrm{Ca}^{2+}$ - and $\mathrm{Mg}^{2+}$-ATPase in the chloroplasts suspension were measured following the method of $\mathrm{Li}$ et al. (2015b).

\section{$\mathrm{H}_{2} \mathrm{O}_{2}$ Concentration and Antioxidant Enzyme Activity}

Following our previous methods, $\mathrm{H}_{2} \mathrm{O}_{2}$ concentration was measured by monitoring the absorbance of titanium peroxide complex at $410 \mathrm{~nm}$ (Zuo et al., 2017). The ascorbate peroxidase (APX) activity was determined by monitoring the decrease

\footnotetext{
${ }^{1}$ http://www.fluoromatics.com/biolyzer_software-1.php
} 
at $290 \mathrm{~nm}$, and the activity of superoxide dismutase (SOD) was measured by monitoring the inhibition of photochemical reduction of nitroblue tetrazolium (NBT) (Zuo et al., 2017). The catalase (CAT) activity was measured as described by Li et al. (2014).

\section{Leaf Pigment Concentration}

Fresh leaf $(0.1 \mathrm{~g})$ was sliced and incubated in $50 \mathrm{ml}$ of pigment extraction solution containing acetone and anhydrous ethanol $(1: 1, \mathrm{v} / \mathrm{v})$ in dark at $25^{\circ} \mathrm{C}$ for $12 \mathrm{~h}$. The supernatant was collected and measurement for absorbance at 663 and $647 \mathrm{~nm}$. Concentrations of total chlorophyll were then calculated according to Arnon (1949).

\section{Leaf ATP Concentration}

The ATP was extracted following the methods of Stewart and Guinn [39] and was measured with the ATP Bioluminescent Assay Kit (Baomanbio, Shanghai, China) as described by Zheng et al. (2009).

\section{Statistical Analysis}

All data were subjected to the one-way ANOVA to determine the significant differences between treatments using the software of
SPSS (Ver. 19.0 SPSS, Chicago, IL, United States). Energy pipeline leaf model of phenomenological fluxes (per cross-section, CS) was performed using the Biolyzer 3.0 software (Bioenergetics Laboratory, Geneva, Switzerland).

\section{RESULTS}

\section{Chl a Fluorescence Transient}

The increase in leaf fluorescence transients in wheat plants under normal temperature treatments (EN and AN) showed a typical OJIP shape (Figure 1A). Under low temperature treatments (EL and $\mathrm{AL}$ ), it showed repressed fluorescence transients, particularly at step I (30 ms) and P (100 ms). The main changes of fluorescence transients were normalized from $\mathrm{O}$ to step $\mathrm{I}$ and step $\mathrm{I}$ to step $\mathrm{P}$ and presented as relative variable fluorescence $\mathrm{W}_{\mathrm{OI}}$ and $\mathrm{W}_{\mathrm{IP}}$, respectively (Figures 1B,C). Significant changes in $\mathrm{W}_{\mathrm{OI}}$ were found between normal temperature treatments and low temperature treatments, which were due to the reductions between PSI and reduced $\mathrm{NADP}^{+}$. Obvious changes in $\mathrm{W}_{\mathrm{IP}}$ during the fast rise period were observed under $\mathrm{EN}, \mathrm{AN}$, and $\mathrm{EL}$, in relation to AL.

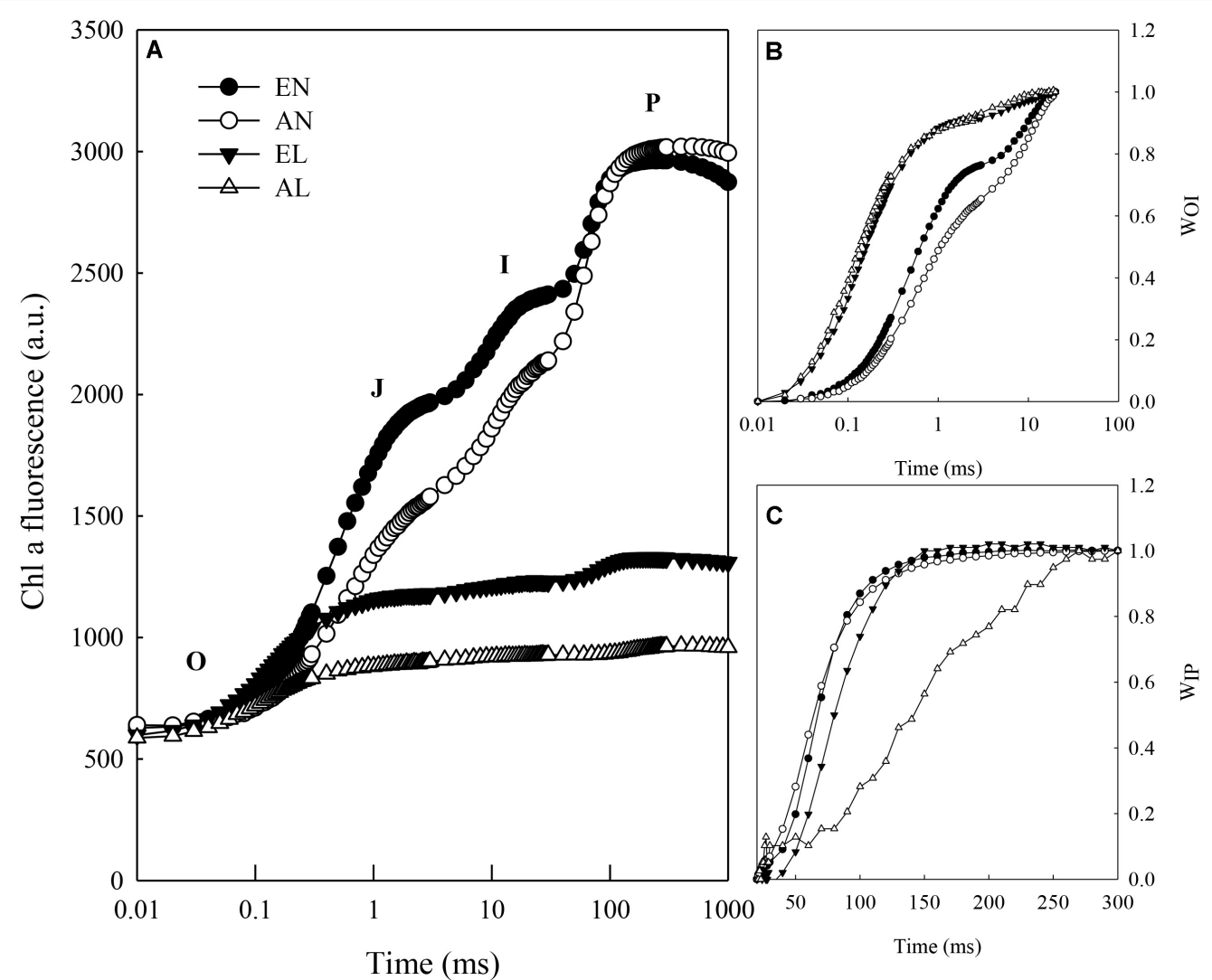

FIGURE 1 | Chlorophyll a fluorescence transient of dark adapted leaves exposed to combination of cold stress and elevated $\mathrm{CO}_{2}$ in wheat. (A) Fluorescence intensity on logarithmic time scale; (B) Variable fluorescence $F_{\mathrm{t}}-F_{0}$ to the amplitude $F_{1}-F_{0}$; (C) Ratio of variable fluorescence $F_{\mathrm{t}}-F_{1}$ to the amplitude $F_{\mathrm{p}}-F_{\mathrm{l}}$. Abbreviations of treatments are explained as followed: $\mathrm{EN}$, elevated $\mathrm{CO}_{2}+$ normal temperature; $\mathrm{AN}$, ambient $\mathrm{CO}_{2}+$ normal temperature; $\mathrm{EL}$, elevated $\mathrm{CO}_{2}+$ low temperature stress; $\mathrm{AL}$, ambient $\mathrm{CO}_{2}+$ low temperature stress. 


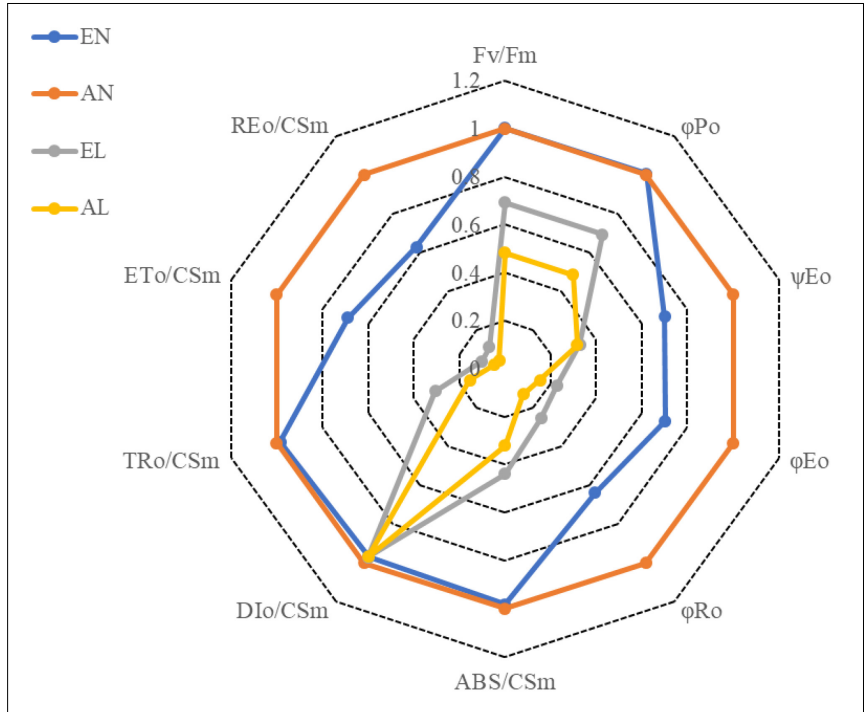

FIGURE 2 | Fluorescence transient Chl a parameters deduced from analysis of the JIP-test of wheat as affected by cold stress and elevated $\mathrm{CO}_{2}$. Abbreviations of treatments are explained in Figure 1. Explanations of these parameters are shown in Table 1.

TABLE 1 | Explanations of selected JIP-test parameters used in the present study.

Fluorescence

parameters

\begin{tabular}{|c|c|}
\hline$F_{O}$ & $\begin{array}{l}\text { Minimal fluorescence, when all PSII RCs (reaction } \\
\text { centers) open }\end{array}$ \\
\hline$F_{\mathrm{V}}=F_{\mathrm{t}}-F_{\mathrm{O}}$ & Variable fluorescence at time $t$ \\
\hline$F_{M}$ & Maximal recorded fluorescence intensity \\
\hline$W_{\mathrm{OI}}=\left(F_{\mathrm{t}}-F_{\mathrm{O}}\right) /\left(F_{1}-F_{\mathrm{O}}\right)$ & $\begin{array}{l}\text { Ratio of variable fluorescence } F_{\mathrm{t}}-F_{\mathrm{O}} \text { to the } \\
\text { amplitude } F_{1}-F_{\mathrm{O}}\end{array}$ \\
\hline$W_{\mathbb{I P}}=\left(F_{\mathrm{t}}-F_{\mathrm{I}}\right) /\left(F_{\mathrm{P}}-F_{\mathrm{I}}\right)$ & $\begin{array}{l}\text { Ratio of variable fluorescence } F_{\mathrm{t}}-F_{\mathrm{I}} \text { to the } \\
\text { amplitude } F_{\mathrm{P}}-F_{\mathrm{I}}\end{array}$ \\
\hline$\varphi \mathrm{PO}$ & $\begin{array}{l}\text { Maximum quantum yield for primary } \\
\text { photochemistry }\end{array}$ \\
\hline$\varphi$ EO & Quantum yield for electron transport (ET) \\
\hline$\varphi_{\mathrm{RO}}$ & $\begin{array}{l}\text { Quantum yield for reduction of end electron } \\
\text { acceptors at the PSI acceptor side (RE) }\end{array}$ \\
\hline$\psi_{E O}$ & Probability that an electron moves further than $Q_{A}$ \\
\hline $\mathrm{TR}_{\mathrm{O}} / \mathrm{CS}_{\mathrm{O}}$ & Trapped energy flux per CS \\
\hline $\mathrm{ET}_{\mathrm{O}} / \mathrm{CS}_{\mathrm{O}}$ & Electron transport flux per CS \\
\hline $\mathrm{RE}_{\mathrm{O}} / \mathrm{CS}_{\mathrm{O}}$ & PSI acceptor per CS \\
\hline $\mathrm{ABS} / \mathrm{CS}_{\mathrm{O}}$ & Absorption flux per CS \\
\hline $\mathrm{Dl}_{\circ} / \mathrm{CS}_{\circ}$ & Non-photochemical quenching per CS \\
\hline
\end{tabular}

Subscript "O" indicates that the parameters refer to illumination onset, when all reaction centers are assumed to be open.

The maximum quantum yield of the PSII (Fv/Fm) were significantly reduced by a 2-day low temperature stress, compared to the normal temperature control (AN); however, the reduction in $\mathrm{Fv} / \mathrm{Fm}$ was more pronounced in $\mathrm{AL}$ than in EL (Figure 2). The interpretations of the selected OJIP test parameters from the $\mathrm{Chl}$ a fluorescence rise transients in different treatments are shown in Table 1. No significant difference in the maximum quantum yield for primary photochemistry $(\varphi \mathrm{PO})$ was found between $\mathrm{EN}$ and $\mathrm{AN}$, while the $\varphi_{\mathrm{PO}}$ in $\mathrm{EL}$ was significantly higher than that in AL. However, there was no significant difference in quantum yield for electron transport (ET) $\left(\varphi_{\mathrm{EO}}\right)$ between EL and AL. The highest value of probability that an electron moves further than $\mathrm{Q}_{\mathrm{A}}\left(\psi_{\mathrm{EO}}\right)$ and quantum yield for reduction of end electron acceptors at the PSI acceptor side (RE) $\left(\varphi_{\mathrm{RO}}\right)$ were found in $\mathrm{AN}$, followed by $\mathrm{EN}$ and $\mathrm{EL}$, and the lowest value was in AL.

The derived parameters from the OJIP curves were summarized by means of energy pipeline leaf model of phenomenological fluxes (per CS) as shown in Figure 3. The energy absorbed per excited cross-section (CSm) (ABS/CSm) in EL was significantly higher than AL. No significant difference in non-photochemical quenching per CSm (Dio/CSm) was observed among these four treatments. The trapped energy flux per $\mathrm{CSm}\left(\mathrm{TR}_{\mathrm{O}} / \mathrm{CSm}\right)$ was similar in $\mathrm{EN}$ and $\mathrm{AN}$, whereas it was higher in EL than AL. The PSI acceptor per CS ( $\left.\mathrm{RE}_{\mathrm{O}} / \mathrm{CSm}\right)$ and electron transport flux per CS (ETo/CSm) was significantly higher in EL, in relation to that in AL. In addition, these two parameters were significantly higher in EN than that in AN. The number of active RCs in PS II CS (shown by open circles in Figure 3) was significantly lower in the plants under low temperature stress, compared with the normal temperature control. It should be noted that the number of active RCs was higher in EL plants than AL plants.

\section{ROS Production and Antioxidant System}

The concentration of $\mathrm{H}_{2} \mathrm{O}_{2}$ in the chloroplasts in flag leaf was significantly increased by $\mathrm{AL}$, compared with $\mathrm{AN}$ (Figure 4). No significant difference was found in leaf $\mathrm{H}_{2} \mathrm{O}_{2}$ concentration between elevated $\left[\mathrm{CO}_{2}\right]$ treatment $(\mathrm{EN})$ and ambient $\left[\mathrm{CO}_{2}\right]$ control (AN). The EL plants had remarkably lower $\mathrm{H}_{2} \mathrm{O}_{2}$ level in chloroplasts compared with AL plants. There was no significant difference in the activities of SOD, APX, and CAT between EN and AN. Interestingly, the SOD activity was significantly higher, while the activities of APX and CAT were lower in AL, in relation to EL.

\section{ATPase Activities, Total Chlorophyll, and ATP Concentrations}

In chloroplasts, the highest activities of $\mathrm{Mg}^{2+}$-ATPase and $\mathrm{Ca}^{2+}$ ATPase were in EN plants, followed by AN and EL, and the lowest values were found in AL (Figure 5). A similar trend was also found in ATP concentration among these treatments (Figure 6). In addition, the total chlorophyll concentration in flag leaf was the highest in AN, while it was the lowest in EL and AL.

\section{DISCUSSION}

Photosynthesis is a highly sensitive process to temperature fluctuations, since it is important to keep the balance between light energy absorbed by photosystems and energy consumed by metabolic sinks (Krček et al., 2008; Brestic et al., 2012; Zivcak et al., 2013). It has been reported that low temperatures exacerbate the imbalance between absorbed light energy and the metabolic sink, thus requiring adjustments of photosynthesis to 


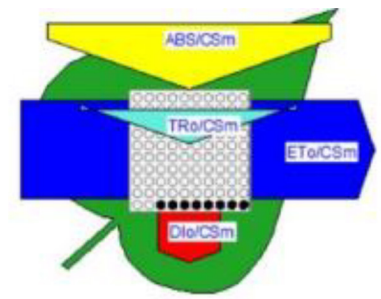

EN

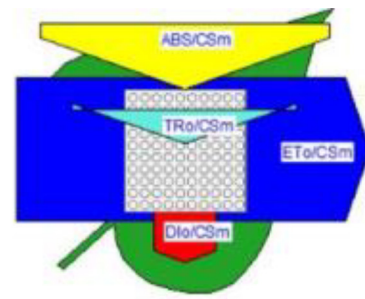

AN

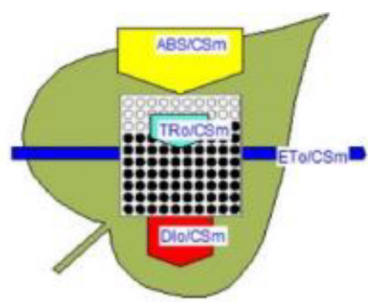

EL

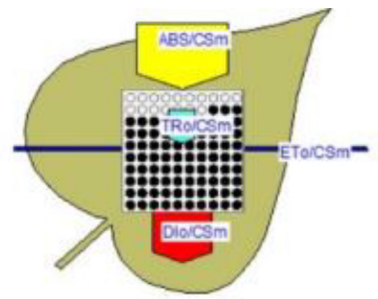

AL

FIGURE 3 | Energy pipeline leaf model of phenomenological fluxes (per cross-section, $\mathrm{CS}$ ) of the flag leaf in wheat as affected by cold stress and elevated $\mathrm{CO}_{2}$. Abbreviations of treatments are explained in Figure $\mathbf{1 .}$

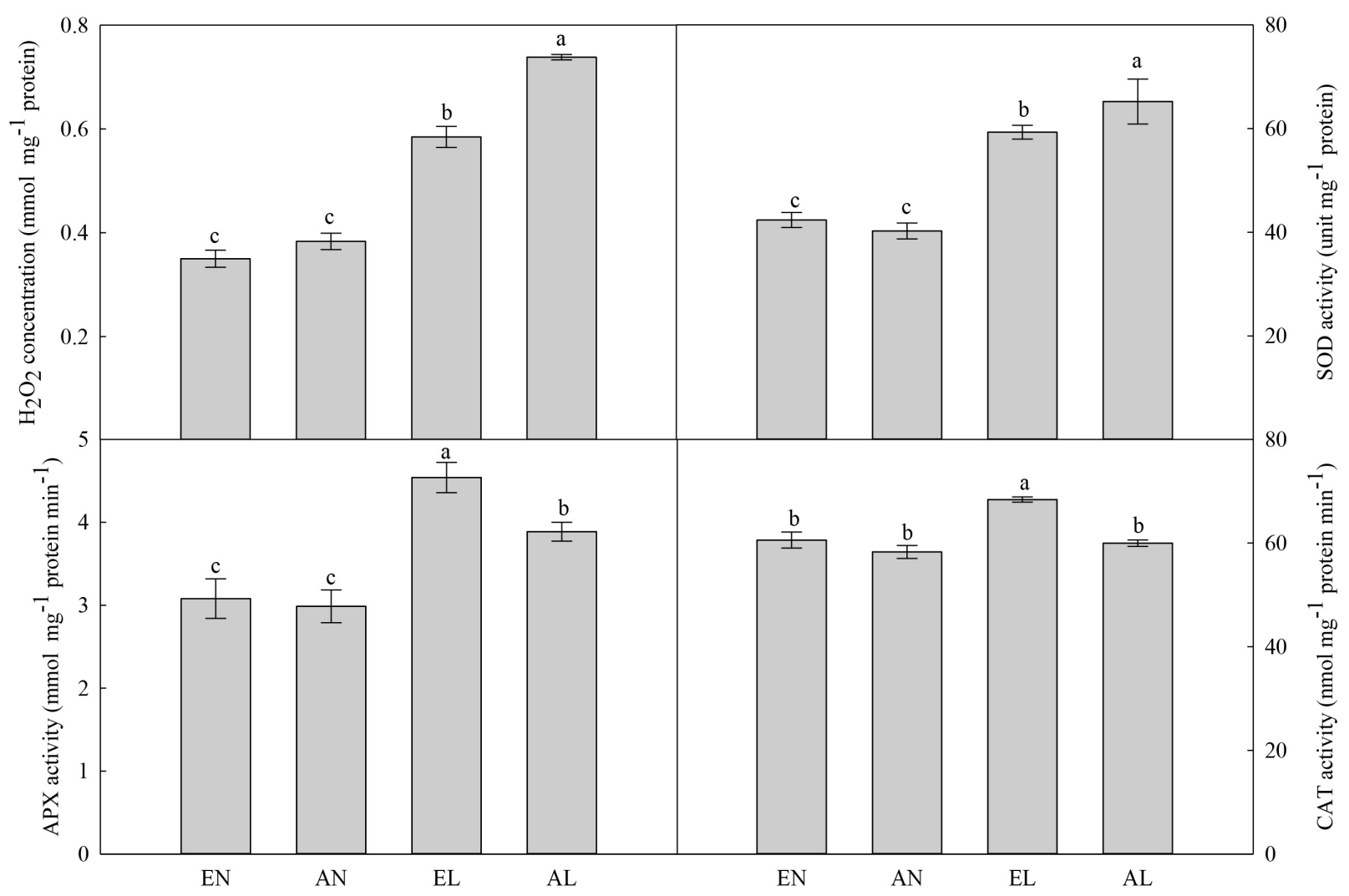

FIGURE 4 | Concentration of $\mathrm{H}_{2} \mathrm{O}_{2}$ and activities of SOD, APX, and CAT in the flag leaf in wheat as affected by cold stress and elevated CO . Abbreviations of treatments are explained in Figure 1. Different small letters mean significant difference at $P<0.05$ level.

maintain the balance of energy flow (Ensminger et al., 2006). Low temperature stress depresses photosynthesis, mainly due to its negative effects on photosynthetic electron transport system (Li et al., 2014). The fast chlorophyll $a$ fluorescence induction curve has been widely used to investigate the photosynthetic electron transport as influenced by abiotic stress, such as low temperature (Strasser, 1987, 1992; Strauss et al., 2006). The present study showed repressed fluorescence transients after a 2day low temperature stress in wheat grown under both ambient and elevated $\left[\mathrm{CO}_{2}\right]$. The I-P phase of the transient fluorescence kinetics indicates the changes in the electron flux from $\mathrm{PQH}_{2}$ to the final electron acceptor and the size of the final electron acceptor pool of PS I (Yusuf et al., 2010). Under ambient $\left[\mathrm{CO}_{2}\right]$, the low temperature stress significantly reduced the electron flux from $\mathrm{PQH}_{2}$ to the final electron acceptor, compared with the normal temperature control. However, the electron flux from $\mathrm{PQH}_{2}$ to the final electron acceptor was similar in low temperature stressed and non-stressed plants under elevated $\left[\mathrm{CO}_{2}\right]$. This indicated that elevated $\left[\mathrm{CO}_{2}\right]$ had a mitigation effect on the damage of low temperature to the electron flux from $\mathrm{PQH}_{2}$ to the final electron acceptor and the sink size of the final electron acceptor of PS I. The O-I part of the kinetics 


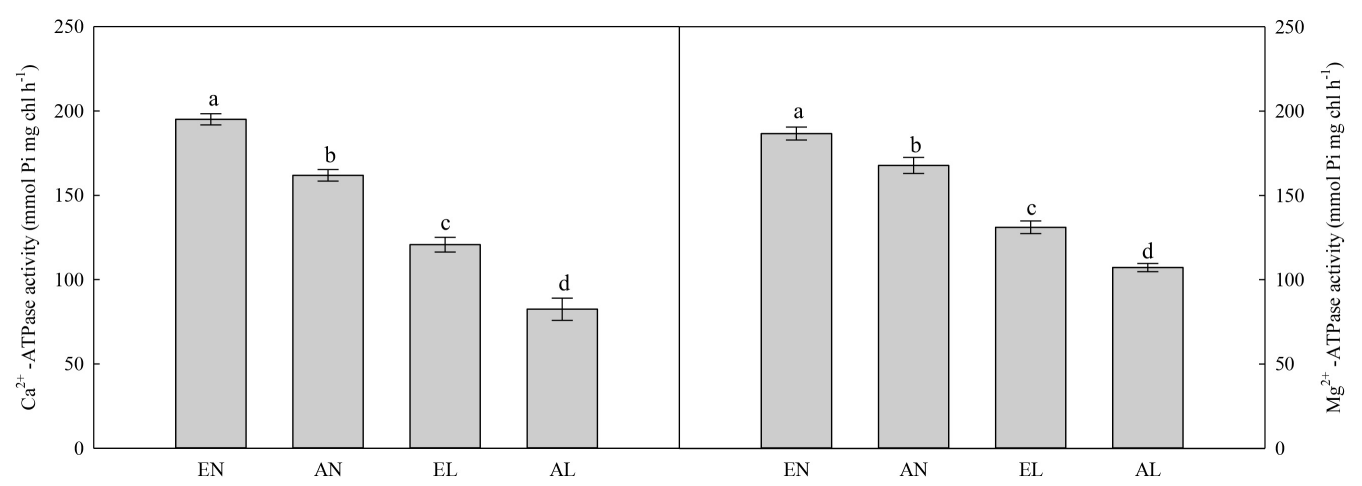

FIGURE 5 | Activities of $\mathrm{Ca}^{2+}$-ATPase and $\mathrm{Mg}^{2+}$-ATPase in the flag leaf in wheat as affected by cold stress and elevated $\mathrm{CO}_{2}$. Abbreviations of treatments are explained in Figure 1. Different small letters mean significant difference at $P<0.05$ level.

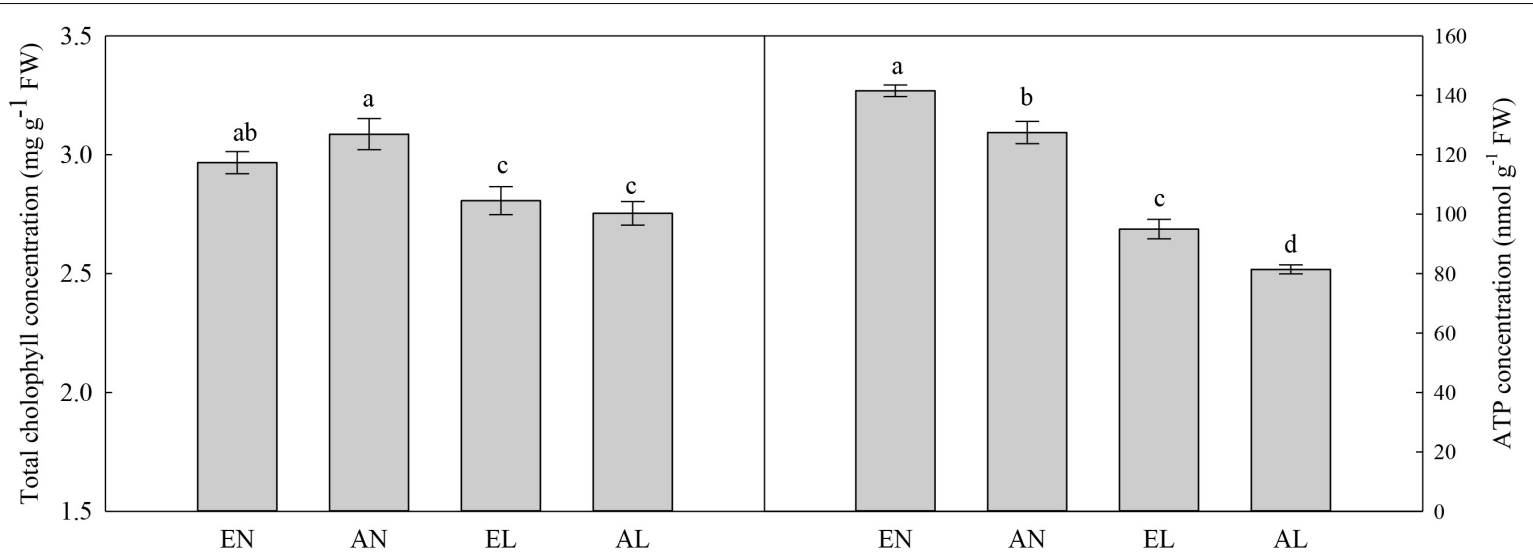

FIGURE 6 | Concentrations of chlorophyll and ATP in the flag leaf in wheat as affected by cold stress and elevated $\mathrm{CO}_{2}$. Abbreviations of treatments are explained in Figure 1. Different small letters mean significant difference at $P<0.05$ level.

was affected by low temperature and elevated $\left[\mathrm{CO}_{2}\right]$, which reveals changes in the process involving exciton capture to $P Q$ reduction (Yusuf et al., 2010). However, the plants under elevated $\left[\mathrm{CO}_{2}\right]$ showed a faster rise in fluorescence transient from $\mathrm{O}$ to I when exposed to low temperature, compared with the plants under ambient $\left[\mathrm{CO}_{2}\right]$, indicating the process involving exciton capture to PQ reduction had a higher efficiency in plants under elevated $\left[\mathrm{CO}_{2}\right]$.

In the present study, the wheat plants under elevated $\left[\mathrm{CO}_{2}\right]$ possessed higher $\mathrm{Fv} / \mathrm{Fm}$ than the plants under ambient $\left[\mathrm{CO}_{2}\right]$ when exposed to low temperature, indicating that the $\left[\mathrm{CO}_{2}\right]$ elevation favors the quantum yield of the PSII under low temperature stress. The efficiency of the light reactions, which is expressed as $\varphi_{\mathrm{Po}_{\mathrm{o}}}$, was observed also higher in the EL plants exposed to low temperature, in relation to AL plants (Chen et al., 2011). When exposed to low temperature, the efficiency balance of the dark reactions after $Q_{A}$, which is reflected by $\psi_{\mathrm{Eo}}$, was similar in plants grown under ambient and elevated $\left[\mathrm{CO}_{2}\right]$. The $\varphi_{\text {Eo }}$ reveals the maximum quantum yield for electron transport beyond $\mathrm{Q}_{\mathrm{A}}$, and it also indicates the maximum quantum yield of primary photochemistry; while $\varphi_{\text {Ro }}$, represents the quantum yield for reduction of end electron acceptors at the PSI acceptor side (RE) (Chen et al., 2011). Here, these two parameters were significantly higher under low temperature stress in wheat grown under ambient and elevated $\left[\mathrm{CO}_{2}\right]$. It indicates that $\left[\mathrm{CO}_{2}\right]$ elevation mitigated the damage to primary photochemistry reaction and protected the end acceptors at the PSI electron acceptor side as well as the activity of ferredoxin$\mathrm{NADP}^{+}$reductase (FNR) in wheat exposed to low temperature stress.

Based on the derived parameters from the chlorophyll a fluorescence induction curve, the leaf model of phenomenological energy fluxes (per CS) was used to show the changes of electron transport process under low temperature and elevated $\left[\mathrm{CO}_{2}\right]$. The ETo/CSm presented the reoxidation of reduced $\mathrm{Q}_{\mathrm{A}}$ via electron transport over a $\mathrm{CS}$ of active and inactive RCs (Mehta et al., 2010). When exposed to the low temperature stress, the plants grown under elevated $\left[\mathrm{CO}_{2}\right]$ showed a higher electron transport efficiency in CS than the plants under ambient $\left[\mathrm{CO}_{2}\right]$. The density of active RCs in PS II CS was also higher in the EL plants, compared with AL plants, which implies that less active RCs were converted into inactive RCs due to $\left[\mathrm{CO}_{2}\right]$ elevation. It should be noted that the energy absorbed per excited $\mathrm{CS}(\mathrm{ABS} / \mathrm{CS}$ ) was higher in EL plants than that in AL plants, 
while non-photochemical quenching (DIo/CSo) was similar in both, indicating that the energy absorption efficiency of PS II was higher in plants grown under elevated $\left[\mathrm{CO}_{2}\right]$; however, the nonphotochemical quenching in plants grown under elevated $\left[\mathrm{CO}_{2}\right]$ was not the main way to maintain the thermo-stability of PSII in exposure to low temperature stress.

Photosynthesis in chloroplasts is one of the main sources of ROS production in plants under abiotic stress (Li et al., 2015a). As a non-radical form of ROS, $\mathrm{H}_{2} \mathrm{O}_{2}$ inactivates the enzymes related to photosynthesis, hence reduces the photosynthetic carbon assimilation ( $\mathrm{Li}$ et al., 2014). Here, the cold-induced increase of $\mathrm{H}_{2} \mathrm{O}_{2}$ concentration was lower in EL plants as compared to AL plants. This was due to the higher activities of APX and CAT. Both antioxidant enzymes can decompose $\mathrm{H}_{2} \mathrm{O}_{2}$ into $\mathrm{H}_{2} \mathrm{O}$ and $\mathrm{O}_{2}$, which are important for scavenging of ROS in plants under abiotic stress (Keunen et al., 2013). The wheat plants grown under elevated $\left[\mathrm{CO}_{2}\right]$ possessed higher ROS scavenging capacity than that under ambient $\left[\mathrm{CO}_{2}\right]$, which benefited for the protection of photosynthetic electron transport system.

Photosynthetic electron transport generates ATP and reduces NADPH to support carbon reduction and ensure effective energy flow for plant growth (Ye et al., 2013). In consistent with the enhanced photosynthetic electron transport efficiency in plants grown under elevated $\left[\mathrm{CO}_{2}\right]$, the ATP production was higher in EL plants compared with AL plants. This was also due to the increased activities of $\mathrm{Mg}^{2+}$-ATPase and $\mathrm{Ca}^{2+}$-ATPase in EL plants under low temperature stress, in relation to $\mathrm{AL}$ plants.

\section{REFERENCES}

Arnon, D. I. (1949). Copper enzymes in isolated chloroplasts. Polyphenoloxidase in Beta vulgaris. Plant Physiol. 24, 1-15. doi: 10.1104/ pp.24.1.1

Ashraf, M., and Harris, P. J. C. (2013). Photosynthesis under stressful environments: an overview. Photosynthetica 51, 163-190. doi: 10.1007/s11099013-0021-6

Benlloch-Gonzalez, M., Bochicchio, R., Berger, J., Bramley, H., and Palta, J. A. (2014). High temperature reduces the positive effect of elevated CO2 on wheat root system growth. Field Crops Res. 165, 71-79. doi: 10.1016/j.fcr.2014. 04.008

Brestic, M., Zivcak, M., Kalaji, H. M., Carpentier, R., and Allakhverdiev, S. I. (2012). Photosystem II thermostability in situ: environmentally induced acclimation and genotype-specific reactions in Triticum aestivum L. Plant Physiol. Biochem. 57, 93-105. doi: 10.1016/j.plaphy.2012.05.012

Chen, S., Zhou, F., Yin, C., Strasser, R. J., Yang, C., and Qiang, S. (2011). Application of fast chlorophyll a fluorescence kinetics to probe action target of 3-acetyl-5isopropyltetramic acid. Environ. Exp. Bot. 73, 31-41. doi: 10.1016/j.envexpbot. 2011.08.005

Dias de Oliveira, E., Bramley, H., Siddique, K. H. M., Henty, S., Berger, J., and Palta, J. A. (2013). Can elevated CO2 combined with high temperature ameliorate the effect of terminal drought in wheat? Funct. Plant Biol. 40, 160-171. doi: 10.1071/FP12206

Ensminger, I., Busch, F., and Huner, N. P. A. (2006). Photostasis and cold acclimation: sensing low temperature through photosynthesis. Physiol. Plant. 126, 28-44. doi: 10.1111/j.1399-3054.2005.00627.x

Frederiks, T. M., Christopher, J. T., Harvey, G. L., Sutherland, M. W., and Borrell, A. K. (2012). Current and emerging screening methods to identify post-heademergence frost adaptation in wheat and barley. J. Exp. Bot. 63, 5405-5416. doi: $10.1093 /$ jxb/ers215

\section{CONCLUSION}

When exposed to low temperature stress, the wheat grown under elevated $\left[\mathrm{CO}_{2}\right]$ had a higher efficiency in photosynthetic electron transport than wheat under ambient $\left[\mathrm{CO}_{2}\right]$. This was due to the enhanced maximum quantum yield for electron transport beyond $\mathrm{Q}_{\mathrm{A}}$ and the increased quantum yield for reduction of end electron acceptors at the PSI acceptor side (RE) in plants under elevated $\left[\mathrm{CO}_{2}\right]$, compared with that under ambient $\left[\mathrm{CO}_{2}\right]$. In addition, the elevated $\left[\mathrm{CO}_{2}\right]$ mitigated the negative effects of low temperature stress on ATP synthesis by enhancing the ATPase activities. The cold tolerance of photosynthetic electron transport system is enhanced in wheat grown under elevated $\left[\mathrm{CO}_{2}\right]$.

\section{AUTHOR CONTRIBUTIONS}

$\mathrm{XL}$ and FL designed the experiments. XZ and XL performed the experiments. LS, SL, FS, FL, and XL wrote and revised the manuscript.

\section{FUNDING}

This research was funded by the the National Key Research and Development Program of China (2018YFD0300201), Villum Foundation Block Stipend (341/300-123012), the National Natural Science Foundation of China (31701362), and CAS Pioneer Hundred Talents Program (C08Y194).

Keunen, E., Peshev, D., Vangronsveld, J., Van Den Ende, W., and Cuypers, A (2013). Plant sugars are crucial players in the oxidative challenge during abiotic stress: extending the traditional concept. Plant Cell Environ. 36, 1242-1255. doi: $10.1111 /$ pce. 12061

Krček, M., Slamka, P., Olšovská, K., Brestič, M., and Benčíková, M. (2008). Reduction of drought stress effect in spring barley (Hordeum vulgare L.) by nitrogen fertilization. Plant Soil Environ. 54, 7-13. doi: 10.17221/2781-PSE

Li, A., Hou, Y., and Trent, A. (2001). Effects of elevated atmospheric CO2 and drought stress on individual grain filling rates and durations of the main stem in spring wheat. Agric. For. Meteorol. 106, 289-301. doi: 10.1016/S0168-1923(00) 00221-5

Li, X., Cai, J., Liu, F., Dai, T., Cao, W., and Jiang, D. (2014). Cold priming drives the sub-cellular antioxidant systems to protect photosynthetic electron transport against subsequent low temperature stress in winter wheat. Plant Physiol. Biochem. 82, 34-43. doi: 10.1016/j.plaphy.2014.05.005

Li, X., Cai, J., Liu, F., Zhou, Q., Dai, T., Cao, W., et al. (2015a). Wheat plants exposed to winter warming are more susceptible to low temperature stress in the spring. Plant Growth Regul. 77, 11-19. doi: 10.1007/s10725-0150029-y

Li, X., Hao, C., Zhong, J., Liu, F., Cai, J., Wang, X., et al. (2015b). Mechanostimulated modifications in the chloroplast antioxidant system and proteome changes are associated with cold response in wheat. BMC Plant Biol. 15:219. doi: 10.1186/s12870-015-0610-6

Li, X., Jiang, H., Liu, F., Cai, J., Dai, T., Cao, W., et al. (2013). Induction of chilling tolerance in wheat during germination by pre-soaking seed with nitric oxide and gibberellin. Plant Growth Regul. 71, 31-40. doi: 10.1007/s10725-0139805-8

Li, Y., Li, X., Yu, J., and Liu, F. (2017). Effect of the transgenerational exposure to elevated $\mathrm{CO} 2$ on the drought response of winter wheat: stomatal control and water use efficiency. Environ. Exp. Bot. 136, 78-84. doi: 10.1016/j.envexpbot. 2017.01.006 
Mäkinen, H., Kaseva, J., Trnka, M., Balek, J., Kersebaum, K. C., Nendel, C., et al. (2017). Sensitivity of European wheat to extreme weather. Field Crops Res. 222, 209-217. doi: 10.1016/j.fcr.2017.11.008

Medina, S., Vicente, R., Amador, A., and Araus, J. L. (2016). Interactive effects of elevated [CO2] and water stress on physiological traits and gene expression during vegetative growth in four durum wheat genotypes. Front. Plant Sci. 7:1738. doi: $10.3389 /$ fpls.2016.01738

Mehta, P., Jajoo, A., Mathur, S., and Bharti, S. (2010). Chlorophyll a fluorescence study revealing effects of high salt stress on Photosystem II in wheat leaves. Plant Physiol. Biochem. 48, 16-20. doi: 10.1016/j.plaphy.2009.10.006

Pinter, P. J., Kimball, B. A., Wall, G. W., Lamorte, R. L., Hunsaker, D. J., Adamsen, F. J., et al. (2001). Free-air CO2 enrichment (FACE): blower effects on wheat canopy microclimate and plant development. Agric. For. Meteorol. 103, 319-333. doi: 10.1016/S0168-1923(00)00150-7

Ruelland, E., Vaultier, M.-N., Zachowski, A., and Hurry, V. (2009). "Chapter 2 Cold signalling and cold acclimation in plants," in Advances in Botanical Research, eds K. Jean-Claude and D. Michel (Cambridge, MA: Academic Press), 35-150.

Sanchez de la Puente, L., Pérez Pérez, P., Martinez-Carrasco, R., Morcuende Morcuende, R., and Martín Del Molino, I. (2000). Action of elevated CO2 and high temperatures on the mineral chemical composition of two varieties of wheat. Agrochimica 44, 221-230.

Shanmugam, S., Kjaer, K. H., Ottosen, C. O., Rosenqvist, E., Kumari Sharma, D., and Wollenweber, B. (2013). The alleviating effect of elevated CO2 on heat stress susceptibility of two wheat (Triticum aestivum L.) cultivars. J. Agron. Crop Sci. 199, 340-350. doi: 10.1111/jac.12023

Stitt, M., and Krapp, A. (1999). The interaction between elevated carbon dioxide and nitrogen nutrition: the physiological and molecular background. Plant Cell Environ. 22, 583-621. doi: 10.1046/j.1365-3040.1999. 00386.x

Strasser, R. J. (1987). "Energy pipeline model of the photosynthetic apparatus," in Progress in Photosynthesis Research, ed. J. Biggins (Dordrecht: Springer), 717-720.

Strasser, R. J. (1992). "The Fo and the OJIP fluorescence rise in higher plants and algae," in Regulation of Chloroplast Biogenesis, ed. J. H. Argyroudi-Akoyunoglou (Boston, MA: Springer), 423-426.

Strauss, A. J., Krüger, G. H. J., Strasser, R. J., and Heerden, P. V. (2006). Ranking of dark chilling tolerance in soybean genotypes probed by the chlorophyll a fluorescence transient O-J-I-P. Environ. Exp. Bot. 56, 147-157. doi: 10.1016/j. envexpbot.2005.01.011

Thakur, P., and Nayyar, H. (2013). "Facing the cold stress by plants in the changing environment: sensing, signaling, and defending mechanisms," in Plant Acclimation to Environmental Stress, eds N. Tuteja and S. S. Gill (New York, NY: Springer Science+Business Media), 29-69.

Varga, B., Vida, G., Varga-László, E., Hoffmann, B., and Veisz, O. (2017). Combined effect of drought stress and elevated atmospheric $\mathrm{CO} 2$ concentration on the yield parameters and water use properties of winter wheat (Triticum aestivum L.) genotypes. J. Agron. Crop Sci. 203, 192-205. doi: 10.1111/jac. 12176
Vicente, R., Perez, P., Martinez-Carrasco, R., Usadel, B., Kostadinova, S., and Morcuende, R. (2015). Quantitative RT-PCR platform to measure transcript levels of $\mathrm{C}$ and $\mathrm{N}$ metabolism-related genes in durum wheat: transcript profiles in elevated [CO2] and high temperature at different levels of $\mathrm{N}$ supply. Plant Cell Physiol. 56, 1556-1573. doi: 10.1093/pcp/pcv079

Wang, L., Feng, Z., and Schjoerring, J. K. (2013). Effects of elevated atmospheric $\mathrm{CO} 2$ on physiology and yield of wheat (Triticum aestivum L.): a meta-analytic test of current hypotheses. Agric. Ecosyst. Environ. 178, 57-63. doi: 10.1016/j. agee.2013.06.013

Whaley, J. M., Kirby, E. J. M., Spink, J. H., Foulkes, M. J., and Sparkes, D. L. (2004). Frost damage to winter wheat in the UK: the effect of plant population density. Eur. J. Agron. 21, 105-115. doi: 10.1016/s1161-0301(03)00090-x

Yan, F., Li, X., and Liu, F. (2017). ABA signaling and stomatal control in tomato plants exposure to progressive soil drying under ambient and elevated atmospheric CO2 concentration. Environ. Exp. Bot. 139, 99-104. doi: 10.1016/ j.envexpbot.2017.04.008

Ye, Z., Robakowski, P., and Suggett, D. J. (2013). A mechanistic model for the light response of photosynthetic electron transport rate based on light harvesting properties of photosynthetic pigment molecules. Planta 237, 837-847. doi: 10. 1007/s00425-012-1790-z

Yusuf, M. A., Kumar, D., Rajwanshi, R., Strasser, R. J., Tsimilli-Michael, M., and Sarin, N. B. (2010). Overexpression of $\gamma$-tocopherol methyl transferase gene in transgenic Brassica juncea plants alleviates abiotic stress: physiological and chlorophyll a fluorescence measurements. Biochim. Biophys. Acta 1797, 1428-1438. doi: 10.1016/j.bbabio.2010.02.002

Zheng, C., Jiang, D., Liu, F., Dai, T., Jing, Q., and Cao, W. (2009). Effects of salt and waterlogging stresses and their combination on leaf photosynthesis, chloroplast ATP synthesis, and antioxidant capacity in wheat. Plant Sci. 176, 575-582. doi: 10.1016/j.plantsci.2009.01.015

Zivcak, M., Brestic, M., Balatova, Z., Drevenakova, P., Olsovska, K., Kalaji, H. M., et al. (2013). Photosynthetic electron transport and specific photoprotective responses in wheat leaves under drought stress. Photosynth. Res. 117, 529-546. doi: 10.1007/s11120-013-9885-3

Zuo, Z., Sun, L., Wang, T., Miao, P., Zhu, X., Liu, S., et al. (2017). Melatonin improves the photosynthetic carbon assimilation and antioxidant capacity in wheat exposed to Nano-ZnO stress. Molecules 22:1727. doi: 10.3390/ molecules 22101727

Conflict of Interest Statement: The authors declare that the research was conducted in the absence of any commercial or financial relationships that could be construed as a potential conflict of interest.

Copyright (C) $2018 \mathrm{Zhu}$, Liu, Sun, Song, Liu and Li. This is an open-access article distributed under the terms of the Creative Commons Attribution License (CC BY). The use, distribution or reproduction in other forums is permitted, provided the original author(s) and the copyright owner(s) are credited and that the original publication in this journal is cited, in accordance with accepted academic practice. No use, distribution or reproduction is permitted which does not comply with these terms. 